\title{
Conservation and development of military sites on Kinmen Island
}

\author{
Y. J. Tseng \& S. Y. Chen \\ National Quemoy University, Taiwan
}

\begin{abstract}
Kinmen, defended by the Chiang Kai-Shek-led national army, were the forefront between China and Taiwan during the Chinese Civil War in 1949. The islands, formerly known as Quemoy, suffered from several bombardments and became a symbol of the Cold War overnight following the Quemoy Crisis in 1958. During this period, the archipelago was mainly populated by the troops with more than 100,000 servicemen stationed here at its peak. Various distinctive military fortifications, massive constructions and special defensive functions were developed and many facilities in preparation for war were constructed in combination with the natural landscape during decades of military rule on the islands. However, the number of troops stationed has been decreasing since the lifting of martial law in 1992. Many military camps have been discarded or abandoned while some were turned into museums or memorial halls by the government to attract tourists. Nevertheless, the majority of the camps have been either closed, disused or demolished. The continuous disappearance of its historic military sites and culture is causing a crisis to Kinmen as a world-famous historic battlefield. This paper aims to present the conservation approaches and challenges of the military sites on the basis of their current status, and to explore possible directions of development for the military sites in Kinmen.
\end{abstract}

Keywords: Cold War, Quemoy Crisis, preservation, re-use.

\section{Introduction}

Kinmen, formerly known as Quemoy, is located off the coast of the Chinese Mainland in the west of the Taiwan Strait. The archipelago, consisting of 12 islands and reefs including Kinmen Island (a.k.a. Greater Kinmen) and Lieyu Island (a.k.a. Little Kinmen), covers a total area of only $150 \mathrm{~km}^{2}$ and is just $1.8 \mathrm{~km}$ 
away from neighbouring islands controlled by the Chinese Mainland at low tide. The agricultural immigration in Kinmen was documented as early as the ninthcentury during the Tang Dynasty. Kinmen became eventually an important defensive island in the southern Fujian, China, after the subsequent migration in the thirteenth century during the Song Dynasty, the fortifications constructed against pirates in the fourteenth century during the Ming Dynasty, and the control and management during the Ching Dynasty. The archipelago is surrounded by land on three sides. Located at the entrance of the Xiamen Bay with a unique environment and topography, Kinmen has been a place of strategic importance in the past centuries.

In 1949, after suffering a series of defeats on the Chinese Mainland, the Nationalist Government retreated to the island of Taiwan with two million troops. Taiwan would serve either as President Chiang Kai-shek's last stand against Communist Chinese forces or as a staging area to retake the mainland [1]. Kinmen and Matsu, located off the Chinese Mainland coast in the west of the Taiwan Strait, were controlled by the Nationalist troops led by Chiang Kai-shek. At the forefront against the Communist People's Liberation Army (PLA), both archipelagos were not only used by Nationalists to prevent the PLA from further assaulting Taiwan but also as an important base for the planned retaking of the Chinese mainland.

The failure of the PLA in Guningtou battle in October 1949 turned Kinmen into the forefront where the two belligerents reached a military stalemate across the strait. When the Korean War started on $25^{\text {th }}$ June 1950, the U.S. President Harry Truman dispatched immediately the Seventh Fleet to neutralise the Taiwan Strait in order to prevent the war from spreading and protect Taiwan [2]. Taiwan has since been under American military protection. Nevertheless, the PLA continued to launch artillery attacks on Kinmen in an attempt to destroy the defence on Kinmen and control the islands in order to assault Taiwan. Following the heavy artillery bombardment by the PLA on 3rd September, 1954 that caused serious military and civilian casualties, more than 57,000 bombs were fired on Kinmen within the first two hours of the 823 Artillery Bombardment on $23^{\text {rd }}$ August, 1958. When the exchange of fire was suspended on $6^{\text {th }}$ October, a total of more than 440,000 shells were landed on Kinmen. The devastating casualties caused the well-known Taiwan Strait Crises during the Cold War [3], otherwise known as the Quemoy Crises [4]. These conflicts have transformed the role of Kinmen from China's first-line defence against external attacks between thirteen to nineteen centuries to the forefront of the US-led communist containment during the Cold War, marking the start of an era of being in the war zone under military administration for Kinmen [5].

Kinmen was under tight military control for 40 years until the martial law was lifted on $7^{\text {th }}$ November, 1992. While most countries underwent rapid economic development in the late 20th century, the militarised Kinmen was accidentally unaffected. As a result, a complete group and large number of MinNan (Southern Fujian) traditional architecture as well as considerable military heritage of the Cold War were preserved and became one of Kinmen's environmental and cultural features. 


\section{Military heritage in Kinmen}

The island of Kinmen, located closely to China, lies mostly within the PLA's artillery firing range; therefore, in order to prevent the PLA from landing or artillery destruction, multiple levels of fortifications have been developed. In its heyday, over one hundred thousand troops were stationed in Kinmen. In addition to barracks, houses, ancestral halls or public buildings were requisitioned to accommodate the large number of servicemen. Tunnels were built under villages, and every resident of Kinmen was recruited and trained as member of the selfdefence force. The facilities established for military purposes or campaign commemoration include broadcast towers for psychological warfare, cultural and recreational centres, war history museums, monuments and military cemeteries. This paper will study the cases of coastal military bases, underground tunnels and important military cultural landscapes to explain their characteristics and values.

\subsection{Coastal military bases}

The north coastline of Kinmen is facing the Chinese Mainland and therefore covered with military bases and fortresses to prevent the PLA from landing. According to the survey in this research, a total of approximately 307 defensive fortresses or bases were stationed along the coastline of 110 kilometres. In other words, there was, on average, one site every 360 meters. In addition, because of the gentle slope at low tide in the North coast, five defensive lines were set up to keep the enemy from entering at high tide. The first line consisted of one to four fences, in accordance to the defence level required, of "rail obstacles" (spiking steel rail placed on a concrete base) in the intertidal zone to prevent the enemy vessels from approaching. The second line was formed with barbed wire on the beach to prevent any person from coming near and surrounding the camp. The third line of defence was the land mines laid in the periphery of the camp, on the beach or even on the rocks. The fourth line was the trenches immediately outside the structures and walls of the camp, such as sisal, thorns and other plants as well as a mixed use of terrain and its features to prevent the enemy from approaching. The last defence line is machine guns, artilleries and other weapons.

In order to defend the flat coast effectively, military bases were mainly deployed in the estuary, flat sandy coast or commanding heights. The bases were deployed in relation to possible landing locations by the enemy, and constructed covered or underground depending on the topography and natural landscape in order to be invisible. Then various forms of bunkers and gun holes were designed and implemented based on the shooting horizon of applicable weapons, and plants compatible to the environment were planted on artificial buildings.

In the case of Longkou First Camp, located on the prominent coast on left side of Longkou village, the gun fortresses were built along the coast to prevent the enemy from landing on the flat sand beach near the estuary of a small river to its left and to protect the nearby coast. There were 16 embrasures and the shooting ranges covering its left and right sides of coast and being part of a mutual protection with its adjacent military fortresses. As the camp was constructed near 
the coast, heavy RC was used for the walls and floors while sisal and turf grass were planted on top of the $60 \mathrm{~cm}$ floor. The troops' living area were enclosed in the concave and surrounded by trenches. Horsetail trees and paper flowers were planted outside, as their abundant branches and thorns may defend against the enemy, while being completely unnoticeable in the surrounding environment. Either from the perspective of appearance, construction, defensive thinking or the natural landscape, the camp is a classic piece of coastal defence.

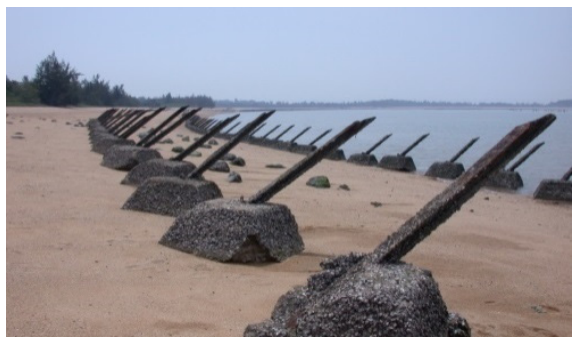

Figure 1: Rail obstacles.

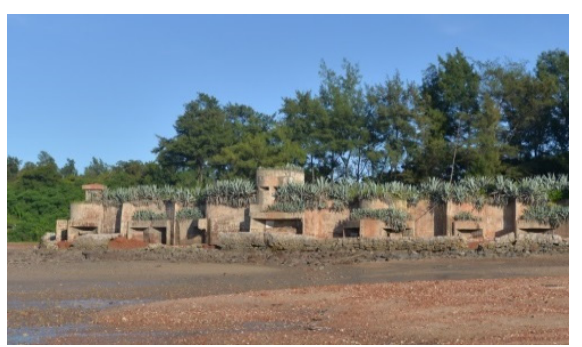

Figure 2: Longkou First Camp.

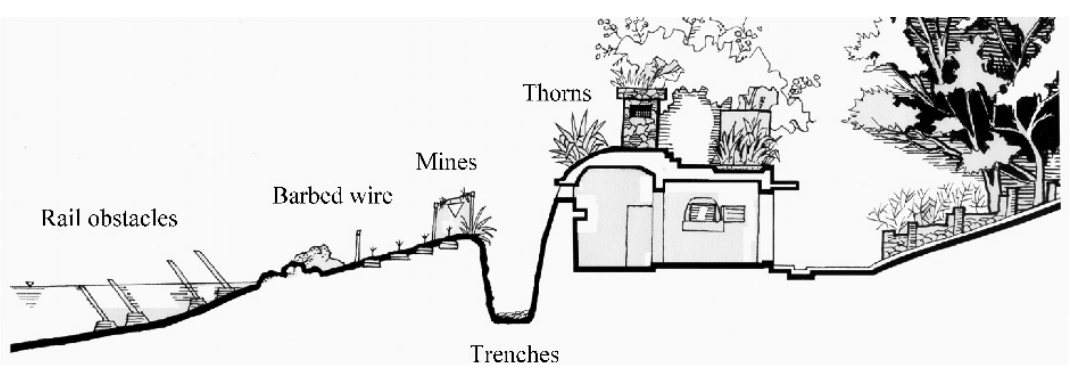

Figure 3: $\quad$ The layout of defensive lines.

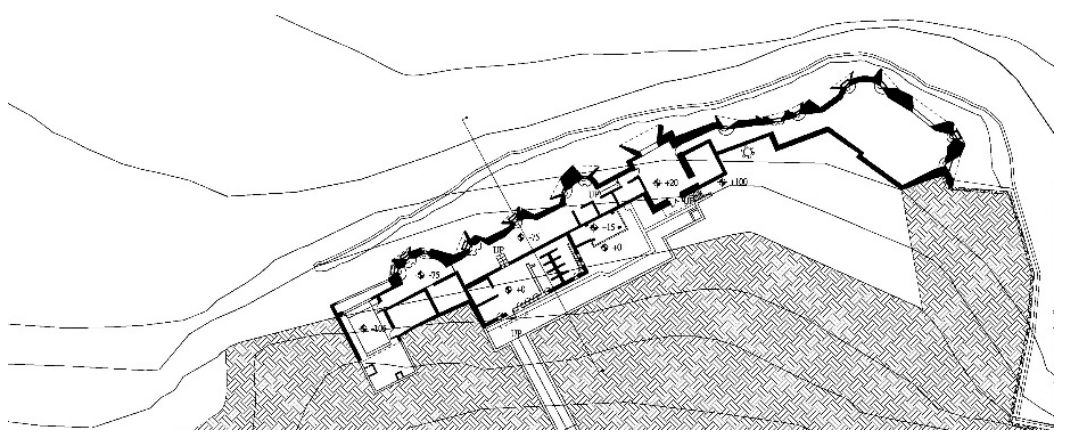

Figure 4: The site plan of the Longkou First Camp. 


\subsection{Underground tunnels}

As Kinmen is made up of granite which is suitable for building tunnels, tunnels were built in hard rocks on the islands with reference to Japan's underground construction experience during the WWII in order to minimize damages from the enemy's artillery assaults and implement the President Chiang Kai-shek's guiding principles of "conserving the fighting force under the ground to unleash the fire power on the ground." A massive tunnel excavation campaign started in 1956. These underground tunnels and military structures allowed Kinmen to safeguard its combat power during intensive shelling.

\subsubsection{Dinghy tunnels}

Dinghy tunnels were excavated from 1962 as part of "Guoguang Plan", Chiang Kai-shek's attempt to retake the mainland. In the sub-project "Golden Whale Project", dinghies would be used for landing assaults on Xiamen (formerly known as Amoy), shipping supplies and support the defence on other islets [6]. This project included the creation of four main dinghy tunnels, among which Jiugong Tunnel on Lieyu Island is the largest. Jiugong Tunnel, adopting a double-T design was completed in two stages in 1965, and the total length of the tunnels is 790 meters with a parking capacity of 52 dinghies. Jhaishan Tunnel, located in south of the Greater Kinmen, can directly access the marine transportation and supply from the Liaoluo Bay. The third construction phase, adopting A-shaped design, completed in 1965, and the total length of the tunnels is 460 meters with a parking capacity of 42 dinghies. Both are 12 meters wide by 7.5 meters high with access to the sea on south cliffs of the islands in order to dodge direct artillery attack and to facilitate the marine transport of supplies.

\subsubsection{Artillery tunnels}

Most of Kinmen's artillery positions use terrain to cover and defend themselves with thick and heavy RC-made cannon bunkers. In 1969, Chiang Kai-shek ordered the Nationalist Army to build a howitzer front for the US-made M115 8-inch howitzer in Shishan (a.k.a. Mt. Lion) in the North East Kinmen, which has a clear and wide view of China, to counter the PLA's shelling from the East. Shishan Howitzer Front, accommodating four 8-inch howitzers, is the only fully tunnelled artillery position in Kinmen and the total length of the 4 meters wide by 4 meters high tunnels is 778 meters.

\subsubsection{Tunnelled base}

In order to ensure prompt defensive networking through tunnels and enhance defending and combating capabilities, a large number of tunnels were excavated to connect forts and barracks. For example, the Chenggong Tunnel, facing Liaoluo Bay in the South of Kinmen, was used to support supply and defence. It was a crucial fully underground base on the coastline with 30 machine guns, 90mm artillery guns and tank guns to block maritime fleet from approaching. 


\subsubsection{Interconnecting tunnels}

In response to the call of "conserving the fighting force underground", chief military command centres and barracks were not only constructed underground but also interconnected by tunnels to shelter personnel from shelling attacks. The tunnels were used as personnel, vehicle and even tank passageway as well as battle operation facilities. Such installations include the famous Central Tunnel of Taiwu Mountain, the Cingtian Hall and the Mashan and Tashan broadcasting posts. The $50 \mathrm{~m} \times 18 \mathrm{~m} \times 11 \mathrm{~m}$ Cingtian Hall was completed in 1962 and can accommodate 1,000 people for massive indoor gathering.

\subsubsection{Civil defence tunnels}

To implement the President Chiang Kai-shek's direction of "being ready for war at any time", the concept of strengthening the organisation of villagers to create combat villages was suggested in 1968 with reference to practices of underground battles in the Vietnam War. The objectives were to turn every villager into a combatant and every village into a combat fort. Therefore, the county's 73 villages were turned into combat villages with 12 villages in strategic locations being selected and appointed the "key combat villages" in 1976. In the key combat villages, additional underground tunnels were built and bunkers were renovated to achieve the target of "militarising the life and embattling the behaviours". Such tunnels include Qionglin and Jincheng civil defence tunnels, the latter of which connects public buildings, hospitals and so on with a total length of 2,560 meters.

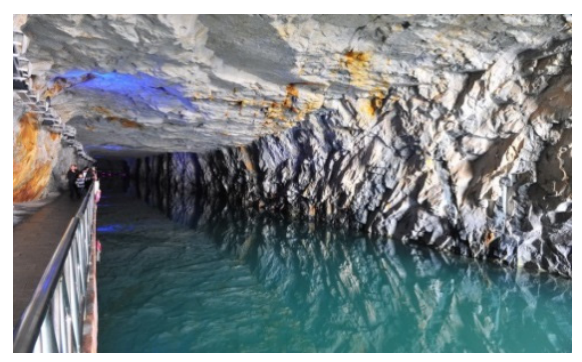

Figure 5: Jhaishan dinghy tunnel.

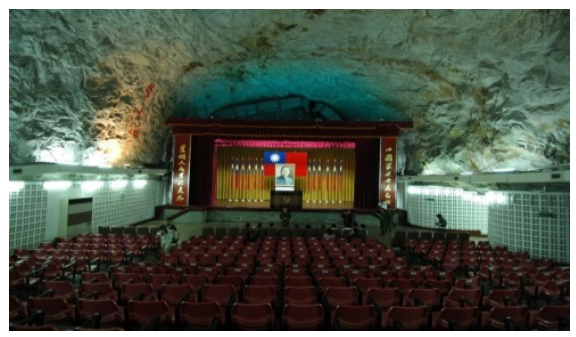

Figure 7: Cingtian Hall with the capacity of 1,000 people.

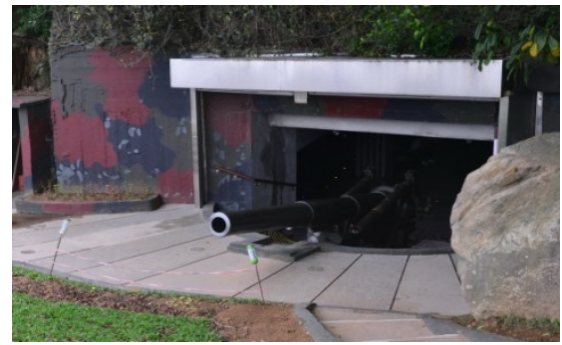

Figure 6: Shishan artillery tunnel.

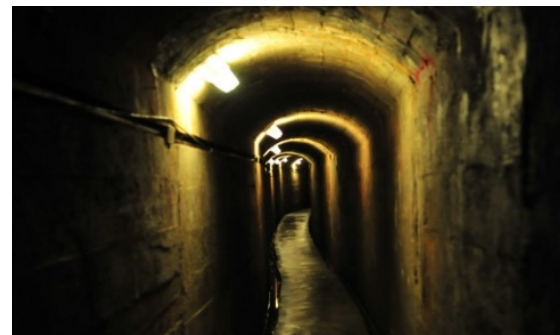

Figure 8: Qionglin civil defence tunnel. 


\subsection{Military cultural landscape}

As Kinmen was developed for military operations and defence during the Cold War, special landscapes of military significance in combination with civil life are still seen everywhere today. For example, the extensive rail obstacles mixed with the traditional oyster fields became a typical agricultural landscape on Kinmen's coastline. Other examples include the anti-airborne RC piles with iron thorns in the sorghum farmlands, the anti-airborne machine gun bunkers at key interactions and the fortresses that may be seen everywhere. The horsetail trees that have been widely planted along the roads leading to the military camps for covering and greening purposes have become representational towering roadside trees of Kinmen. Besides, still left to be seen today on the walls of houses in villages are military bulletin boards, propaganda banners and slogans, such as "Obedience to the Supreme Leader", "Carry Forward the Kinmen Fighting Spirit", "CivilMilitary Cooperation", "Fight Against Odds", "Rescue Our Brothers in Mainland", "Restore the Lost Land", etc. These banners provide a glimpse of the integrated civil-military community and the battlefront life and culture under the massive presence of troops of those days.

Besides, in order to commemorate the war, monuments have been erected at important locations and intersections. For example, the three "August 23 Artillery Battle Victory Monuments" in commemoration of the Quemoy Crisis in 1958, the "Unsung Heroes Monument" in commemoration of the soldiers who lost their lives and the bearers of morale boosters such as "Hold Kinmen and Matsu in Order to Keep Penghu and Taiwan, Keep Peng and Taiwan in Order to Restore the Mainland", etc. These slogans have also become one of the representational cultural characteristics of Kinmen.

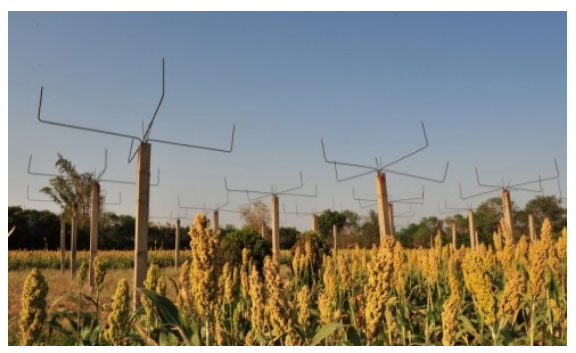

Figure 9: Anti-airborne piles.

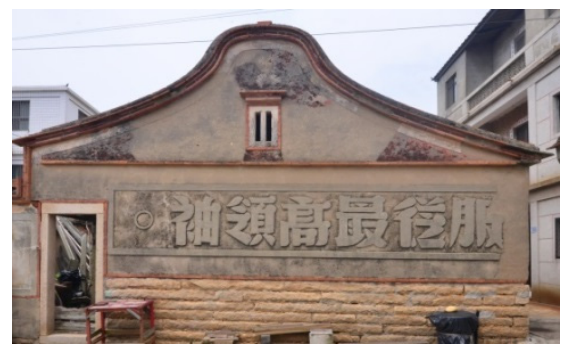

Figure 10: "Obedience to the supreme leader."

\section{Current status of military sites}

During the Cold War, Kinmen was mainly populated by the troops with more than 100,000 servicemen stationed here at its peak. The martial law was lifted in 1992, after 43 years of military control. The Kinmen National Park was later set up in 1995 to preserve the military sites and monuments, conserve cultural heritage as well as sustain the natural resources. However, the number of stationed troops has 
been reducing since the lifting of martial law in Kinmen. Before the lifting of martial law in 1992, there were still 60,000 troops. When the Armed Forces Refining Program was completed in 2001 and the Mini three links were established across the strait, the number has dropped dramatically to less than 20,000 that year. With less than 10,000 in 2010, the garrison has been further downsized to 3,000 servicemen in 2014. According to the survey, there were 512 military camps and bases in Kinmen in 2006, yet a large number would be abandoned later after the troops were reduced. Until 2015, a total number of 181 camps and bases would have been released. To take full advantage of the barracks and buildings, the Kinmen National Park Administration (KNP), the Kinmen County government and local town and township administrations took over and adaptively reused some sites as public buildings, military history museums, memorial halls or other recreational venues. However, most of the military camps were either closed, disused or demolished, and Kinmen, as a world famous historic battleground, is consequently facing a crisis of significantly losing its military sites and ambiance.

\subsection{Reuse of military sites}

To meet the strong demand for operational facilities, some private-owned lands in Kinmen were occupied by the armed forces, and then through purchase at a low price since the 1970s. As the troops were reduced, the land used by the army has gradually been released. The relevant regulations allow the original landowners to repurchase the land that has been released, with standing structures being removed, at current land values, and if no official agencies acquire it. In consequence, only a few of the numerous military camps and bases were reused by official agencies, of which the majority were transferred to and reused by the Kinmen National Park Administration and the Kinmen County Tourism Department. As 2014 ends, the KNP will have taken over 42 such properties, while the Tourism Department will have taken over thirteen. The survey of this research found that the KNP uses or plans to use eleven of such properties received for recreation or exhibition, followed by five for museums of the war history of the specific bases and four for educational experience; and the Tourism Department uses or plans to use six such sites for educational experience, followed by four for recreation and exhibition. In summary, the KNP takes over and reuses the released barracks mainly as historic battle monuments and theme-based exhibitions, while

Table 1: $\quad$ List of military sites reuse.

\begin{tabular}{lcccccc}
\hline & $\begin{array}{c}\text { War } \\
\text { History } \\
\text { Museum }\end{array}$ & $\begin{array}{c}\text { Recreation/ } \\
\text { Theme } \\
\text { Gallery }\end{array}$ & $\begin{array}{c}\text { Educational } \\
\text { Experience }\end{array}$ & Other & Unplanned & Total \\
\cline { 2 - 7 } & 5 & 11 & 4 & 4 & 19 & 42 \\
\cline { 2 - 7 } Kinmen National \\
$\begin{array}{l}\text { Kinmen Tourism } \\
\text { Department } \\
\quad \text { Subtotal }\end{array}$ & 0 & 4 & 6 & 1 & 2 & 13 \\
\cline { 2 - 7 } & 5 & 14 & 12 & 3 & 20 & 55 \\
\hline
\end{tabular}


the Tourism Department reuses them for educational experience and recreation in principle.

In addition to the mentioned ways of reuse, the Forestry Research Institute transformed a received barrack into a botanical garden, and adapted some of the artillery forts into a veteran's memorial hall and tourist information centres.

\subsection{Disuse and demolition of military sites}

As the number of the troops stationed in Kinmen decreased significantly, some barracks are kept according to the rule of being "closed at peace time and reused at wartime", some were handed to various official agencies for reuse, and the others were all returned to the original landowners after all buildings are demolished. As a result, since 2010, a large number of military camp buildings had been demolished before the lands were retrieved by original owners. Some of the demolished military buildings were sites of important historic military events, of significant military values or of common souvenir for millions of servicemen or veterans who were once stationed here. Unfortunately, they were all destroyed and demolished due to the absence of pre-assessment of cultural heritage values or the original owner's repurchase intention regardless of the heritage values.

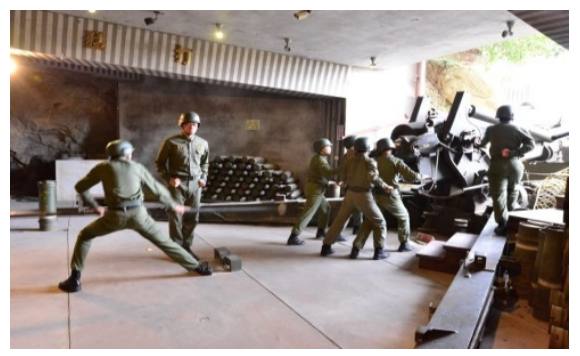

Figure 11: Howitzer exercise at Shishan.

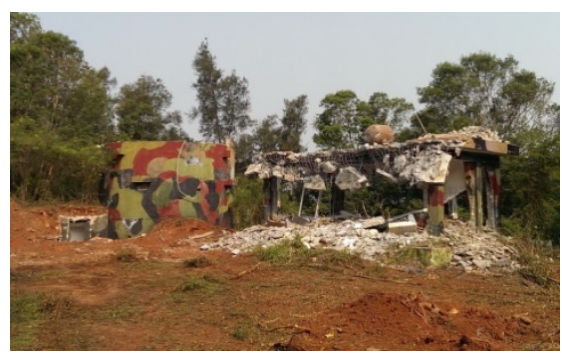

Figure 12: Turned-down military base.

\section{Challenges and reflections on military sites conservation}

With the constructions built for operations and defence as well as the facilities suited for local terrains and landscapes, Kinmen has been one of the rare Cold War sites of historic significance. The 43 years of martial law put the local society under great pressure. The traumatic war experience and the military installations remain to be seen here today and can be used as a reminder of the absurdity of war and the preciousness of peace. However, the army has released massive military properties in recent years in response to the pressure of urbanization and land development as well as the fact of weakening military demands. As a result, many important military sites have been destroyed, creating a great challenge for military space conservation. 


\subsection{Challenges in conservation}

During the military control, Kinmen was run by a unified military-civil administration. As military operations came as the top priority, the space was fully militarised and the civilians' life was also largely sacrificed. For example, the administration was entitled to expropriate private lands. The local residents were also deprived of democracy, freedom and convenience under the tight military control. Therefore, the lifting of martial law deregulated the space and life, too. Meanwhile, the arising development pressure and the soaring land prices today put the conservation of military sites in great difficulties.

\subsubsection{Soaring property and land prices and development}

After the establishment of the Mini Three Links in 2001, geographically convenient Kinmen has become an important transport hub between Taiwan and China. Investors are attracted and casting their greedy eyes on Kinmen while the growth of the West Coast Economic Zone in China has been expanding in recent years. Therefore, urbanization accelerates and construction projects are springing up. As a result, the value of land and properties are rocketing. The price of a flat in urban Kinmen, for example, escalated from approximately 750 Euros per square meter in 2008 to 2,000 Euros in 2013, while the price of agricultural land increased from approximately 70 Euros per square meter to 140-200 Euros. When a piece of army-used land is released, the original owner is entitled to repurchase at a price lower than market price in hope for land development. However, the removal of the ground objects caused the destruction of many valuable military buildings.

\subsubsection{Lack of cultural heritage awareness}

After the lifting of martial law, on the one hand, local residents are still accustomed to the military control and find nothing special about military camps and bases. The barracks, tunnels, fortresses and slogans are just a part of their everyday life, and they are not fully aware of the distinctiveness of the military heritage. On the other hand, some people see the construction left behind by the army as creations under oppression that do not worth conserving, or even as bearer of bad memories. Moreover, in the current atmosphere of rapid construction, the pursuit of new materials and demolition of old items are not only popular, but also a compensation for the inability to afford construction during the military control period.

\subsubsection{Impact of unhealthy politics and insufficient regulations}

In consideration of the public rights and interests, even barracks or historic military sites of historical significance were often removed without any identification of heritage value. On the one hand, it's due to the political interference. When the original owners intend to fully repurchase the lands sold to the army at low prices, they would politically prevent cultural value assessment. On the other hand it's due to incomplete regulations on capacity transfer and land swapping. Therefore, the land and ground objects of military camps cannot be conserved by preserving the values or transferring the right to develop. And some government officials manage passively or eliminate the cultural heritage value 
assessment procedures under pressure. With or without the ground objects removed, the military spaces are thus released for repurchase without investigation nor potential positioning and development studies.

\subsection{Reflections on military sites conservation}

The Conservation of military sites in Kinmen should not be limited to conserving important historical evidence, but also in safeguarding the value from the contemporary historic view of the reflections on war and the pursuit of peace.

\subsubsection{Recognizing the values of military sites}

The baptism of war is an indelible history for Kinmen, and the military camps and sites will be sole and representational physical witness of Kinmen's road from the war to the peace. The remaining fortification structures, despite being probably not refined or getting damaged due to the time factor, are important exhibits for the younger generations to ponder the history and commemorate the sacrifices made by the earlier generation. The distinctive value of the camps should be viewed in the framework of military operations and defence of Kinmen. The assessment should be made rather from the perspective of comprehensive operational thinking than based on the value of land, construction or environment. The inspirational touching stories behind should not be neglected despite the current run-down status. The value of a military site lies in its historical depth and cultural broadness. The conservation can only be better recognised and further improved by promoting public education and strengthening their awareness of the links between cultural heritage and history.

\subsubsection{Preservation of military cultural landscape}

The military facilities and organisations in Kinmen are mainly defence-oriented. From the coastline to the hills, from over the ground to under the ground, from training bases to logistics, and in politics, economics and education, the defenceoriented layout is reflected on every aspect. Therefore, the significance of military camps and battlefront culture can be redefined by identifying their value through a comprehensive review of the military camps on their positions, coherence between sites and particularities in the construction methods from the perspective of defence and counter-attack. The stories between "people and the environment" should be told as well to demonstrate the historical facts and memory of the tragic military-civil coexistence. Furthermore, the various camps, bases and structures along with the collective memory of Kinmen residents can be registered as a "military cultural landscape" for integral protection and sustainable development project under the legal protections of Taiwan's "Cultural Heritage Preservation Act”.

\subsubsection{Responsibilities of the authorities}

For the historic military sites in Kinmen, a key challenge for survival is the absence of pre-assessment on value and failure to register for legal protection before the land release, attributed to the insufficient protection laws and orders and the authorities that are passive in action. In cases where the conservation of valuable 
historic military sites is in conflict with the respect for private land ownership and protection of original owners' rights and interests, the authorities may take advantage of transfer of right to develop and land swapping, or even take initiative to use public funding to provide protection by designation or registration as cultural landscape. Meanwhile, compensation for the loss of interests in the land should be taken into account, so that the original landowners will be more willing to collaborate for the implementation of heritage protection.

\subsubsection{Proactive re-use planning}

As previously mentioned, the current reuses of released sites are mainly for recreation and theme-based exhibition. The usage remains to be at the stage of static display and passive use, lacking the notion of comprehensive global planning. In the future, after an overall value and resource assessment, the sites should be conserved as battlefront cultural landscape. The idea of eco-museum should also be introduced with the tangible heritage, such as the battlefield, bunkers, military bases, tunnels and monuments, and the intangible heritage, such as battlefield history, battlefield life, battlefield literature, etc, being systematically integrated into planning. Even the concept of "dark tourism" may be considered, so that lessons can be learned from history through exposure to battlefront culture and heritage value. Furthermore, the principle of "conservation first and economic sustainability comes second" should be applied through a good adaptive reuse project, so that the objectives of cultural tourism and sustainable development of the sites may be achieved.

\section{Conclusion}

When promoting the cultural heritage preservation and the cultural tourism vision, it is indispensable to outreach and educate the local residents of the value and significance of their own heritage. We must understand that it is easy to demolish yet impossible to fully restore. The history and culture behind Kinmen's military heritage is the substantial support of the sustainable heritage conservation. A rootbased preservation by the citizens in Kinmen can be possible only when Kinmense are fully informed of the values of these military heritage sites and encouraged by appropriate interpretation and promotion. The values of the camps lie not only in their historical significance and the particularity of military facilities, but also in the overall significance of the military administration period when every civilian was defending the island and the battlefront culture of the interacting settlements and residents. In order to conserve the precious heritage of the Cold War, comprehensive protection measures should be developed through regulation reviews, land use planning, property compensation, adaptive reuse, NGO support and community human resource training. After a complete survey on military resources of different types, adaptive reuse and eco-museum should be the planning direction. Making good use of these military sites and their resources in a timely and appropriate manner to meet the future demands of cultural tourism, will shed light on the significance and vale of the sites from a more macroscopic 
and comprehensive point of view and help to move towards a sustainable environment development.

\section{References}

[1] Hickey, Dennis Van Vranken, United States - Taiwan Security Ties: From Cold War to Beyond Containment, Westport, Connecticut: London, 1994.

[2] Ball, Simon J., The Cold War: An International History, 1947-1991, Arnold: London, 2001.

[3] Garver, John W., The Sino-American Alliance: Nationalist China and American Cold War strategy in Asia, M.E. Sharpe: New York, 1997.

[4] Liu, Lee-hsuan, (ed.). The 1958 Quemoy Crisis: An Oral History, Armed Force Museum: Taipei, 2009. (In Chinese.)

[5] Szonyi, Michael, Cold War Island: Quemoy on the Front Line, Cambridge University Press: Cambridge, 2008.

[6] Jean, Sheue-Lin (ed.) Kinmen's World Heritage Potential Sites: Cold War Landscape, Cultural Affairs Bureau of Kinmen: Kinmen, 2013. (In Chinese.) 